Article

\title{
Catalytic roles of the acid sites in different pore channels of H-ZSM-5 zeolite for methanol-to-olefins conversion
}

\author{
Sen Wang a, Zhikai Li a , Zhangfeng Qin a,*, Mei Dong a, Junfen Li a, Weibin Fan a,\#, Jianguo Wang a,b,\$ \\ a State Key Laboratory of Coal Conversion, Institute of Coal Chemistry, Chinese Academy of Sciences, Taiyuan 030001, Shanxi, China \\ b University of the Chinese Academy of Sciences, Beijing 100049, China
}

\section{A R T I C L E I N F}

\section{Article history:}

Received 14 September 2020

Accepted 10 November 2020

Available online 5 March 2021

\section{Keywords:}

Methanol-to-olefins

H-ZSM-5 zeolite

Acid site distribution

Density functional theory calculation

Molecular dynamic simulation

\begin{abstract}
A B S T R A C T
H-ZSM-5 zeolite is a typical catalyst for methanol-to-olefins (MTO) conversion. Although the performance of zeolite catalysts for MTO conversion is related to the actual location of acid sites in the zeolite framework, the catalytic roles of the acid sites in different pore channels of the H-ZSM-5 zeolite are not well understood. In this study, the MTO reaction network, involving the aromatic cycle, alkene cycle, and aromatization process, and also the diffusion behavior of methanol feedstock and olefin and aromatic products at different acid sites in the straight channel, sinusoidal channel, and intersection cavity of H-ZSM-5 zeolite was comparatively investigated using density functional theory calculations and molecular dynamic simulations. The results indicated that the aromatic cycle and aromatization process occurred preferentially at the acid sites in the intersection cavities with a much lower energy barrier than that at the acid sites in the straight and sinusoidal channels. In contrast, the formation of polymethylbenzenes was significantly suppressed at the acid sites in the sinusoidal and straight channels, whereas the alkene cycle can occur at all three types of acid sites with similar energy barriers and probabilities. Consequently, the catalytic performance of H-ZSM-5 zeolite for MTO conversion, including activity and product selectivity, can be regulated properly through the purposive alteration of the acid site distribution, viz., the location of $\mathrm{Al}$ in the zeolite framework. This study helps to elucidate the relation between the catalytic performance of different acid sites in the H-ZSM-5 zeolite framework for MTO conversion, which should greatly benefit the design of efficient catalyst for methanol conversion.
\end{abstract}

(C) 2021, Dalian Institute of Chemical Physics, Chinese Academy of Sciences. Published by Elsevier B.V. All rights reserved.

\section{Introduction}

Methanol-to-olefins (MTO) conversion is considered a potential non-petroleum method for preparing lower olefins from multifarious carbon sources [1-3]. Different types of zeolites, and particularly H-ZSM-5 and H-SAPO-34 zeolites, can be used as catalysts for MTO conversion. When H-SAPO-34, a CHA-type (cage topology with an aperture size of $3.8 \AA \AA 3.8 \AA ̊$ ) zeolite, was used as catalyst for MTO conversion, it exhibited high selectivity for $\mathrm{C}_{2}-\mathrm{C}_{4}$ olefins (approximately 90\%). However, it

\footnotetext{
* Corresponding author. Tel: +86-351-4046092; Fax: +86-351-4041153; E-mail: qzhf@sxicc.ac.cn

\# Corresponding author. Tel: +86-351-4199009; E-mail: fanwb@sxicc.ac.cn

$\$$ Corresponding author. Tel: +86-351-4199009; E-mail: iccjgw@sxicc.ac.cn

This work was supported by the National Key R\&D Program of China (2018YFB0604802), the National Natural Science Foundation of China (21991092, 21991090, U1910203, 21802157), the Natural Science Foundation of Shanxi Province of China (201901D211581), Excellent Doctoral Student Award and Subsidy Program of Shanxi Province (BK2018001), and the Independent Research Project of State Key Laboratory of Coal Conversion, Institute of Coal Chemistry, CAS (2020BWZ004).
}

DOI: 10.1016/S1872-2067(20)63732-9 | http://www.sciencedirect.com/journal/chinese-journal-of-catalysis | Chin. J. Catal., Vol. 42, No. 7, July 2021 
was rapidly deactivated owing to carbonaceous deposition and would require continuous regeneration in practice [4,5]. In contrast, the H-ZSM-5 zeolite, an MFI-type zeolite with two-dimensional sinusoidal channels ( $5.1 \AA \times 5.5 \AA$ ) intersected with one dimensional straight channels $(5.3 \AA \times 5.6 \AA)$, presented much greater catalytic stability for MTO conversion. However, the product contained an appreciable amount of $\mathrm{C}_{4+}$ hydrocarbons, which needed to be recycled. To improve the catalytic activity and target product selectivity in practice or to analyze the reaction mechanism and structure-performance relationship theoretically, MTO conversion has been extensively investigated recently [6-10]. Typically, MTO conversion can be divided into induction (formation of the first ethene and propene species), transition (construction of the initial cyclic intermediates), and steady (continuous production of light olefins) periods. The formation of the first $\mathrm{C}-\mathrm{C}$ bonds during the induction period might conform to the direct reaction mechanism via different intermediates, such as methoxymethyl cations, formate and acetate cations, and surface methyleneoxy analogues [11-16]. Subsequently, the first ethene and propene species can quickly construct methylcyclopentadiene and methylbenzene, which act as the initial hydrocarbon pool (HCP) species, through a series of reactions including methylation, deprotonation, dealkylation, hydride transfer, and cyclization [17]. During the steady period, which contributed the most to the production of lower olefins, MTO conversion occurs via a dual cycle HCP mechanism, including the aromatic and alkene cycles [18-20]. For the aromatic cycle, polymethylbenzenes (polyMBs) act as the main HCP species [21-25], whereas for the alkene cycle, light olefins are produced via the successive methylation of lower olefins and cracking of $\mathrm{C}_{3+}$ alkenes [26-28].

The performance of zeolite catalysts for MTO conversion is closely related to their acidic properties. In addition, the quantity, strength and distribution of acid sites in the zeolite framework present critical effects on catalytic activity and stability and product selectivity. As the acid sites of zeolites originate from the isomorphous substitution of $\mathrm{Al}$ for Si at different zeolite framework lattice sites [29-31], the changes in the location of $\mathrm{Al}$ or the distribution of acid sites in zeolite frameworks can change the environment of the active acid center and the shape-selectivity of the pore channels that determine the specific reaction pathways and product distribution during MTO conversion [32-35].

The catalytic performance of zeolites for MTO conversion was reported to depend on the location of $\mathrm{Al}$ atoms or acid sites in zeolite frameworks [36-38]. Chen et al. [39] determined that for MTO conversion over H-MCM-22 zeolite, the acid sites located in the surface pockets and supercages were prone to carbonaceous deposition, whereas the acid sites in the sinusoidal channels were the main catalytically active centers during the steady reaction stage. Moreover, the acid sites in the sinusoidal channels favored the alkene cycle, which preferentially produced higher olefins. Liu et al. [40] reported that, for MTO conversion over high-silica $\mathrm{H}$-Beta zeolite, when $\mathrm{Al}$ atoms were enriched at the T9 sites, a high selectivity for propene (49.7-58.3\%) and a long catalytic lifetime ( $>20 \mathrm{~h})$ were achieved owing to the predominance of the alkene cycle. Li et al. [41] suggested that doping the H-ZSM-5 zeolite with B during synthesis could shift the location of $\mathrm{Al}$ atoms into the $10-\mathrm{MR}$ channels of H-ZSM-5 zeolite and, thus, prolong catalyst lifetime from 25 to $45 \mathrm{~h}$ and increase selectivity for propene from $30 \%$ to $40 \%$. Yokoi et al. [42] used a post-synthesis method to prepare CON-type zeolite with $\mathrm{Al}$ atoms preferentially inserted into the larger pores, viz., the 12-MR pores rather than the 10 -MR pores. The CON-type zeolite presented a longer catalytic lifetime than Beta and ZSM-5 zeolites and a high selectivity of approximately $80 \%$ for $\mathrm{C}_{3}-\mathrm{C}_{4}$ olefins. Recently, Zhang et al. [43] observed that the incorporation of B into H-RUB-13 zeolite used for MTO conversion could help to increase the number of accessible $\mathrm{Al}$ atoms at the T1 and T2 sites, which could subsequently increase the number of catalytically effective acid sites and enhance the catalytic performance of H-RUB-13 zeolite for MTO conversion .

The acid sites of H-ZSM-5 zeolite accessible for MTO conversion can be classified into three types according to their location, viz. straight channel (T7, T8 and T11), sinusoidal channel (T4 and T10), and intersection cavity (T1, T2, T3, T5, T6, T9 and T12) sites [37]. The location of acid sites in the zeolite framework is known to affect the catalytic performance of H-ZSM-5 zeolite for MTO conversion. Several studies have demonstrated that an optimized location of $\mathrm{Al}$ atoms or acid site distribution in zeolite frameworks can enhance catalytic activity and stability and improve selectivity for specific olefin products during MTO conversion [33,36,44-46]. Liang et al. [45] demonstrated that more ethene and aromatic species could be produced on H-ZSM-5 zeolite with a higher number of intersection cavity acid sites, which was prepared using tetraethyl orthosilicate as the Si source, whereas H-ZSM-5 with a higher number of straight and sinusoidal channel acid sites, which was prepared using silica sol as the Si source, presented higher selectivity for propene and $\mathrm{C}_{3+}$ alkenes. Kim et al. [46] adjusted the crystallization temperature and prepared several H-ZSM-5 zeolites with different distributions of $\mathrm{Al}$ atoms in the framework; moreover, they demonstrated that an increase in the number of intersection cavity acid sites could promote the formation of aromatic HCP intermediates, leading to a marked increase in the initial MTO catalytic activity and the ethene-to-propene ratio in the products.

However, the catalytic roles of the acid sites located in different pore channels of H-ZSM-5 zeolite is poorly understood owing to the complexity of the MTO reaction network, which involves numerous elemental reactions, such as methylation, deprotonation, cracking, elimination, hydride transfer, and cyclization. For example, the effects of acid site distribution on the intrinsic kinetics of different elementary reactions and the diffusion behavior of reactants and products have not been elucidated yet.

In this study, the free energy barrier $\left(\Delta G_{\text {int }^{\ddagger}}\right)$, rate constant $(k)$, and free energy $\left(\Delta G_{\mathrm{R}}\right)$ of each reaction step for the aromatic cycle, alkene cycle, aromatization process, successive methylations of the benzene ring, and diffusion of methanol, propene, benzene, $p$-xylene, and hexamethylbenzene were calculated and comparatively analyzed using density functional theory 
(DFT) calculations and molecular dynamic (MD) simulations. The results revealed the possible effect of the location of $\mathrm{Al}$ atoms or distribution of acid sites on the intrinsic reaction kinetics for the formation of different HCP species and their evolution in subsequent reaction processes at molecular/atomic level, which should benefit the design of efficient catalysts for methanol conversion.

\section{Computational modeling and methods}

\subsection{MTO conversion kinetics over H-ZSM-5 zeolite}

The $\Delta G_{\text {int }}{ }^{\ddagger}, k$, and $\Delta G_{\mathrm{R}}$ values of each reaction step of the aromatic cycle, alkene cycle, aromatization process, and successive methylations of the benzene ring were calculated using three 120T cluster models (Fig. 1 and Fig. S1), which were derived from the periodic structure of H-ZSM-5 zeolite. The acid sites in the intersection cavity, sinusoidal channel and straight channel were simulated by siting one $\mathrm{Al}$ atom at $\mathrm{T} 12, \mathrm{~T} 10$, and T8 sites, respectively, on the basis of the calculated substitution energy and occupation probability for $\mathrm{Al}$ siting at different sites in the H-ZSM-5 framework [47]. The 120T cluster models contained $119 \mathrm{Si}$ and $1 \mathrm{Al}$ atoms, corresponding to a Si/Al atomic ratio of 119 , which was in good agreement with the $\mathrm{Si} / \mathrm{Al}$ atomic ratio of typical H-ZSM-5 zeolite catalysts for MTO conversion. The peripheral $\mathrm{Si}$ atoms in these models were saturated with $\mathrm{H}$ atoms, in the same direction of Si-O bonds, and the $\mathrm{Si}-\mathrm{H}$ bond length was $1.47 \AA$ A.

DFT calculations were performed using the Gaussian 09.E01 package [48]. A combined theoretical model, ONIOM ( $\omega$ B97X-D/6-31G (d,p): PM6), was used for all geometry optimizations and frequency calculations. This method has been used in previous theoretical investigation and has been demonstrated to be rather effective and reliable for MTO conversion over zeolite catalysts $[23,27,47]$. The $14 \mathrm{~T}$ active region and reacting molecules were fully relaxed and were considered
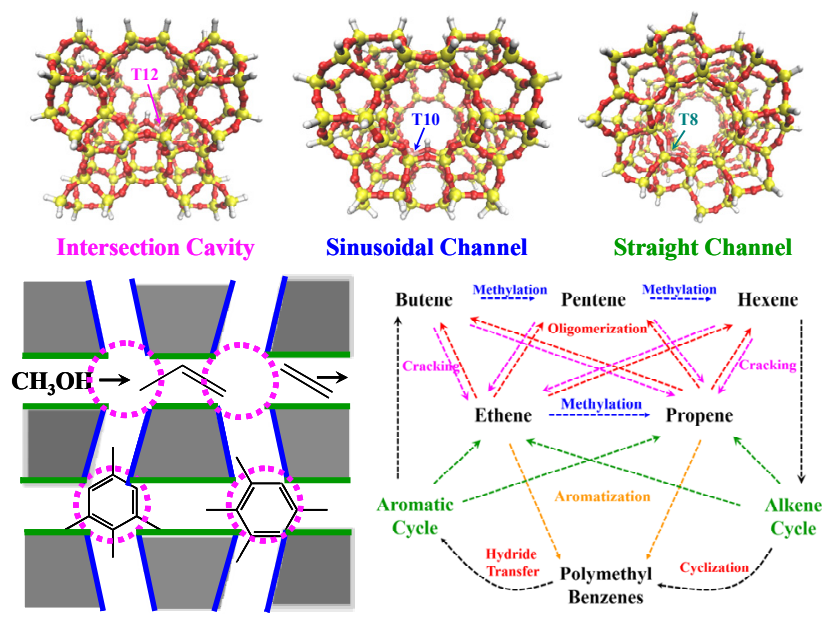

Fig. 1. 120T cluster models illustrating the intersection cavities, sinusoidal channels, and straight channels (T12, T10, and T8 sites, respectively) of H-ZSM-5 zeolite ( $\mathrm{Si}$, yellow; $\mathrm{O}$, red; Al, pink; and $\mathrm{H}$, white). Schematic topological structure of H-ZSM-5 zeolite. Methanol-to-olefins conversion reaction network including aromatic and alkene cycles following the dual-cycle hydrocarbons pool mechanism. to be the high layer, whereas the rest of the structure was fixed and served as the low layer. Transition states (TSs) were identified using the OPT = TS method and were confirmed using the quasi-internal reaction coordinate approach to verify that each TS was connected with the corresponding reactants and products. Furthermore, TSs are first-order saddle points on the potential energy surface with only one imaginary frequency. It was demonstrated that the obtained reactants and products were situated at the energy minima points on the potential energy surface with only real frequencies. To obtain accurate interaction energies, single-point calculations with the 6-311G (2df, $2 p$ ) basis set were refined using the $\omega$ B97X-D functional including dispersion interactions $[49,50]$. The free energy $(\Delta G)$ was obtained from the $\omega$ B97X-D/6-311G (2df, 2p) total electronic energy and the thermal correction from the ONIOM ( $\omega$ B97X-D/6-31G (d, p): PM6) frequency calculation using the partial Hessian vibrational analysis method at $723 \mathrm{~K}$, which included the atoms that were relaxed during geometry optimization. The following equation, which was based on the classical TS theory, was used to calculate $k$ at $723 \mathrm{~K}$ [51]:

$$
k=\frac{k_{B} T}{h} \exp \left(-\Delta G_{\text {int }}^{\neq} / R T\right)=\frac{k_{B} T}{h} \exp \left(\Delta S_{\text {int }}^{\neq} / R\right) \exp \left(-\Delta H_{\text {int }}^{\neq} / R T\right)
$$

where $k_{\mathrm{B}}$ is the Boltzmann's constant; $h$ is the Planck's constant; and $\Delta H_{\text {int }^{*}}$ and $\Delta S_{\text {int }^{*}}$ are the changes in standard molar enthalpy and entropy between reactants and the TS, respectively, at $723 \mathrm{~K}, T$ is the absolute temperature, and $R$ is the ideal gas constant.

\subsection{Diffusion of methanol, alkenes, and aromatics in H-ZSM-5 zeolite}

The diffusion of methanol, propene, $p$-xylene, and hexamethylbenzene in the intersection cavities, sinusoidal channels, and straight channels of H-ZSM-5 zeolite was investigated using MD simulations utilizing the Sorption and Forcite module in the Material Studio 7.0 software with the canonical ensemble [52]. The temperature was set to $723 \mathrm{~K}$ and was controlled using a single Nosé-Hoover thermostat with a time step of $1.0 \mathrm{fs}$. The COMPASS force field was used and the velocity Verlet algorithm was performed to integrate the Newton's equations of motion [53], which could appropriately describe the diffusion and adsorption of small molecules in zeolite frameworks [54]. The long-range electrostatic interactions were calculated using the Ewald summation method and the Lennard-Jones interactions were calculated using a $12.8 \AA$ A cutoff radius [55]. Ten methanol, propene, $p$-xylene, or hexamethylbenzene molecules were placed inside a $2 \times 2 \times 2$ supercell of H-ZSM-5 zeolite ( $a=$ $40.156 \AA$, $b=39.788 \AA$, and $c=26.744 \AA$ ) and all involved atoms, including those in the zeolite framework, were fully relaxed. For methanol, propene, and $p$-xylene, the starting configurations were acquired from their adsorption on H-ZSM-5 zeolite, whereas hexamethylbenzene was directly placed in the intersection cavities owing to the significant steric hindrance in the sinusoidal and straight channels. All geometries were optimized before MD simulations. The trajectory was recorded every 500 steps during the production stage. 


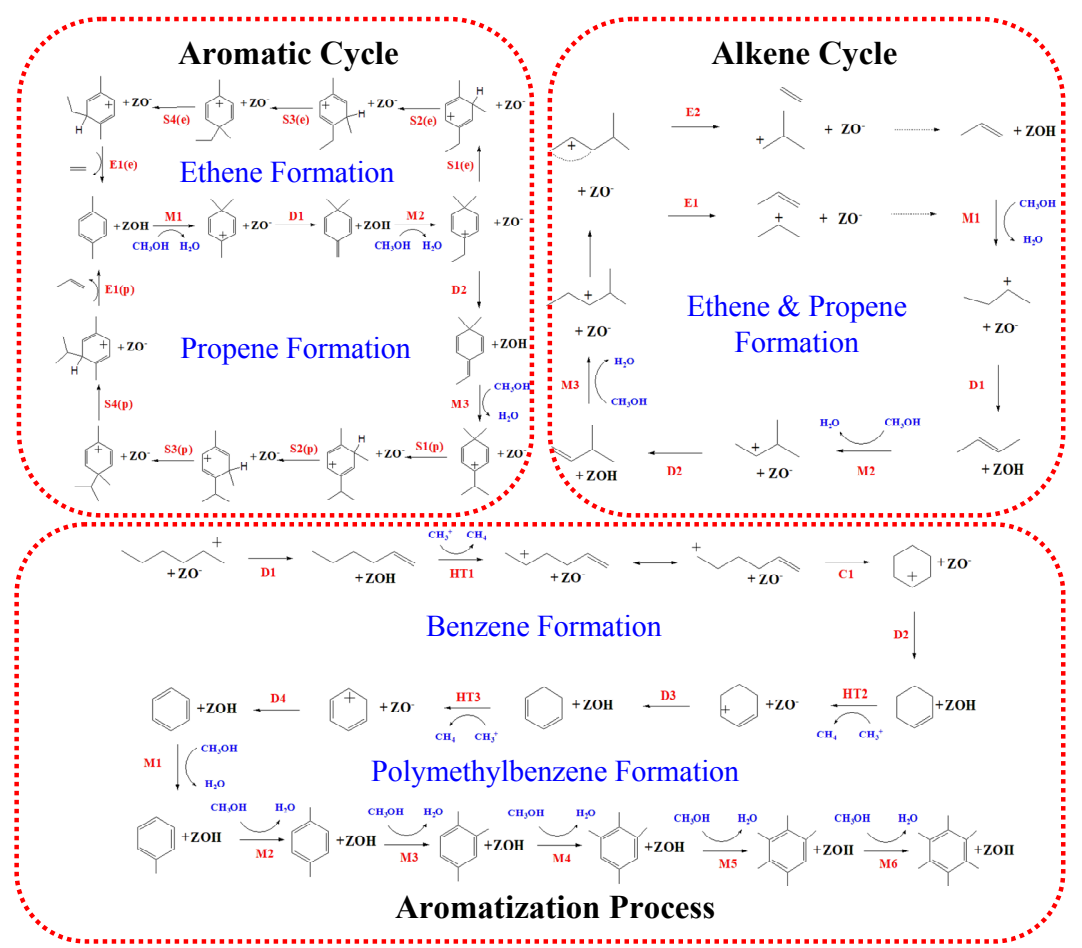

Fig. 2. Reaction networks for the aromatic cycle, alkene cycle, and aromatization process during methanol-to-olefins conversion over H-ZSM-5 zeolite.

\section{Results and discussion}

Fig. 2 illustrates the detailed reaction scheme for the formation of light olefins (ethene and propene) and aromatics (benzene and polymethylbenzenes) through the aromatic cycle, alkene cycle, and aromatization process during MTO conversion. To evaluate the effect of acid strength on MTO conversion, the proton affinity (PA), methanol adsorption free energy ( $\left.E_{\mathrm{MeOH}-\mathrm{ads}}\right)$, and ammonia adsorption free energy ( $\left.E_{\mathrm{NH} 3-\mathrm{ads}}\right)$ at the T8, T10 and T12 acid sites of H-ZSM-5 zeolite were calculated, and the results are presented in Table S1 and Fig. S2. The calculated PA values at the T8, T10, and T12 acid sites were 1125,1135 , and $1119 \mathrm{~kJ} \mathrm{~mol}^{-1}$, respectively. These results indicated that the intrinsic acid strength of the T8, T10, and T12 acid sites in the H-ZSM-5 zeolite framework were similar and were in line with previously reported data $[56,57]$. In addition, the $E_{\mathrm{MeOH} \text {-ads }}$ and $E_{\mathrm{NH} 3 \text {-ads }}$ values for the T8, T10, and T12 acid sites were similar: 12,6 , and $7 \mathrm{~kJ} \mathrm{~mol}^{-1}$, and $-110,-128$, and $-118 \mathrm{~kJ} \mathrm{~mol}^{-1}$, respectively.

Moreover, our recent theoretical study indicated that for the conversion of methanol into methoxy groups, as the TS for the formation of methoxy groups was relatively small and the interactions of the methoxy groups with the surrounding pore channels of H-ZSM- 5 zeolite near the acid sites were weak, the T8, T10, and T12 acid sites of H-ZSM- 5 zeolite presented similar $\Delta G_{\mathrm{int}^{*}}$ and $\Delta G_{\mathrm{R}}$ values, viz. 89,83 , and $79 \mathrm{~kJ} \mathrm{~mol}-1$, and -26 , -30 , and $-14 \mathrm{~kJ} \mathrm{~mol}^{-1}$, respectively [47]. These results implied that the relatively small differences in acid strength between the T8, T10, and T12 acid sites and the actual locations of these acid sites in the H-ZSM- 5 zeolite framework did barely affect the activation of methanol. Therefore, for simplicity, in this study, the effect of the acid strength of different acid sites in the H-ZSM-5 zeolite framework was excluded when considering the effect of acid site location on MTO conversion behavior.

\subsection{Aromatic cycle}

For the formation of ethene and propene via the aromatic cycle, methanol was first adsorbed on the acid sites of H-ZSM-5 zeolite located near the sites where aromatic HCP species (represented by $p$-xylene) were co-adsorbed (Fig. 2). The aromatic cycle started with the gem-methylation of $p$-xylene with methanol (M1) to form the 1,1,4-trimethylbenzenium cation, which subsequently lost a proton from the methyl group and formed 1,1-dimethyl-4-methylene-2,5-cyclohexadiene with an exocyclic double bond (D1). The second methanol molecule attacked the exocyclic double bond to form a 1,1-dimethyl-4-ethyl benzenium cation (M2), from which ethene was formed through successive alkyl side-chain shifts (S1(e)-S4(e)) and elimination (E1(e)). Alternatively, the 1,1-dimethyl-4-ethylbenzenium cation formed the 1,1-dimethyl-4-isopropyl benzenium cation via deprotonation (D2) and methylation (M3); thereafter, propene was produced through alkyl side-chain shifts (S1(p)-S4(p)) and elimination (E1(p)), which was similar to the formation of ethene [58,59].

The free energy profiles, reaction kinetic data, and free energies for each step of the formation of ethene and propene via the aromatic cycle of MTO conversion at the T8, T10, and T12 acid sites of H-ZSM-5 zeolite are comparatively illustrated in Fig. 3 and Table 1. The optimized TSs for the methylation and olefin elimination steps are presented in Figs. S3 and S4. Reaction M1 was the rate-determining step for the aromatic cycle. The T12 acid sites presented the lowest $\Delta G_{\text {int }}{ }^{\ddagger}$ and the highest $k$ 

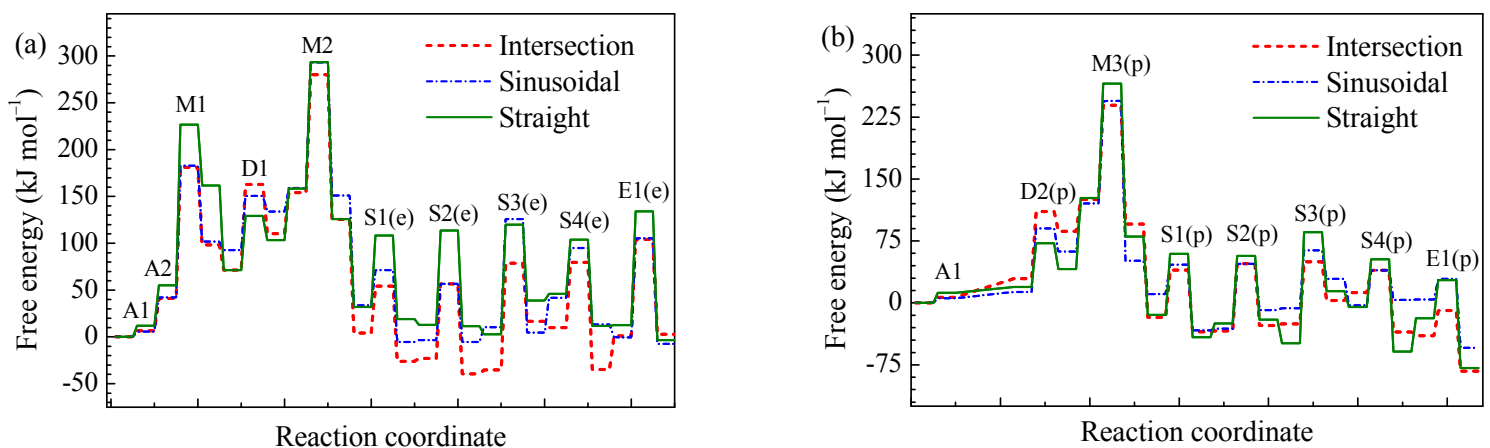

Fig. 3. Free energy profiles of (a) ethene (e) and (b) propene (p) formation via the aromatic cycle at $723 \mathrm{~K}$ during methanol-to-olefins conversion at the acid sites in the intersection cavities, sinusoidal channels, and straight channels of H-ZSM- 5 zeolite. A1 and A2 denote the adsorption of methanol and co-adsorption of $p$-xylene, respectively, M1-M3 denote methylation reactions, D1 and D2 denote deprotonation reactions, S1-S4 denote alkyl side-chain shifting reactions, and $\mathrm{E} 1$ denotes olefin elimination reaction.

values of all types of acid sites for the methylation step (114-140 kJ mol-1 and $1.17 \times 10^{3}-8.91 \times 10^{4} \mathrm{~s}^{-1}$, respectively), followed by the T10 acid sites (124-141 kJ mol-1 and $1.04 \times$ $10^{3}-1.64 \times 10^{4} \mathrm{~s}^{-1}$, respectively), and the T8 sites (135-171 kJ $\mathrm{mol}^{-1}$ and $6.11 \times 10^{0}-3.01 \times 10^{3} \mathrm{~s}^{-1}$, respectively). Similarly, the T8 acid sites presented relatively high $\Delta G_{\text {int }^{\neq}}$values for the subsequent alkyl migration (S1-S4) and olefin elimination (E1) steps. Furthermore, the T12 acid sites presented a lower apparent free energy barrier (AFE, the energy difference between the highest point and the zero point in the free energy profiles) for the aromatic cycle $\left(280 \mathrm{~kJ} \mathrm{~mol}^{-1}\right)$ than the T10 and T8 acid sites (293 and $294 \mathrm{~kJ} \mathrm{~mol}^{-1}$, respectively) $[60,61]$. These results were ascribed to the steric hindrance and space confinement effect in the narrow straight and sinusoidal channels being stronger than those in the intersection cavities, which can sup- press the configuration transformation of aromatic HCP species and intermediates [33,34].

The aforementioned results indicated that the T12 acid sites favored the aromatic cycle compared with the T10 and T8 acid sites. Moreover, because the rate-determining step for the formation of propene and ethane was the same, ethene and propene should be produced simultaneously with similar probabilities via the aromatic cycle of MTO conversion over H-ZSM-5 zeolite, regardless of the acid site location; this was consistent with previously reported results [59].

\subsection{Alkene cycle}

Higher carbenium ions can be produced from propene through successive methylations (M1, M2, and M3) and depro-

\section{Table 1}

Calculated free energy barrier $\left(\Delta G_{\text {int }^{\ddagger}}\right)$, rate constant $(k)$, and reaction free energy $\left(\Delta G_{\mathrm{R}}\right)$ of each reaction step for the formation of ethene and propene via the aromatic cycle of methanol-to-olefins conversion at the acid sites in the intersection cavities (T12), sinusoidal channels (T10), and straight channels (T8) of H-ZSM-5 zeolite at $723 \mathrm{~K}$.

\begin{tabular}{|c|c|c|c|c|c|c|c|c|c|}
\hline \multirow{2}{*}{ Step } & \multicolumn{3}{|c|}{$\Delta G_{\text {int }^{*}}\left(\mathrm{~kJ} \mathrm{~mol}{ }^{-1}\right)$} & \multicolumn{3}{|c|}{$k\left(\mathrm{~s}^{-1}\right)$} & \multicolumn{3}{|c|}{$\Delta G_{\mathrm{R}}\left(\mathrm{kJ} \mathrm{mol}{ }^{-1}\right)$} \\
\hline & $\mathrm{T} 12$ & $\mathrm{~T} 10$ & T8 & T12 & $\mathrm{T} 10$ & T8 & $\mathrm{T} 12$ & $\mathrm{~T} 10$ & T8 \\
\hline \multicolumn{10}{|c|}{ Ethene (e) formation } \\
\hline M1 & 140 & 141 & 171 & $1.17 \times 10^{3}$ & $1.04 \times 10^{3}$ & $6.11 \times 10^{0}$ & 57 & 60 & 107 \\
\hline M2 & 126 & 136 & 135 & $1.23 \times 10^{4}$ & $3.01 \times 10^{3}$ & $3.01 \times 10^{3}$ & -29 & -8 & -32 \\
\hline D1 & 91 & 58 & 58 & $3.87 \times 10^{6}$ & $9.65 \times 10^{8}$ & $9.75 \times 10^{8}$ & 39 & 41 & 32 \\
\hline $\mathrm{S} 1(\mathrm{e})$ & 50 & 37 & 76 & $3.74 \times 10^{9}$ & $2.96 \times 10^{10}$ & $4.73 \times 10^{7}$ & -30 & -39 & -13 \\
\hline $\mathrm{S} 2(\mathrm{e})$ & 80 & 60 & 101 & $2.68 \times 10^{7}$ & $6.70 \times 10^{8}$ & $7.97 \times 10^{5}$ & -16 & -2 & -1 \\
\hline $\mathrm{S} 3(\mathrm{e})$ & 114 & 115 & 117 & $8.64 \times 10^{4}$ & $6.75 \times 10^{4}$ & $5.32 \times 10^{4}$ & 52 & -6 & 36 \\
\hline $\mathrm{S} 4(\mathrm{e})$ & 70 & 53 & 58 & $1.37 \times 10^{8}$ & $2.12 \times 10^{9}$ & $9.92 \times 10^{8}$ & -45 & -28 & -34 \\
\hline E1(e) & 103 & 106 & 122 & $5.47 \times 10^{5}$ & $3.38 \times 10^{5}$ & $2.50 \times 10^{4}$ & -4 & -7 & -16 \\
\hline \multicolumn{10}{|c|}{ Propene (p) formation } \\
\hline M3 & 114 & 124 & 138 & $8.91 \times 10^{4}$ & $1.64 \times 10^{4}$ & $1.50 \times 10^{3}$ & -30 & -69 & -47 \\
\hline D2 & 81 & 77 & 53 & $2.03 \times 10^{7}$ & $4.03 \times 10^{7}$ & $2.25 \times 10^{9}$ & 57 & 49 & 22 \\
\hline $\mathrm{S} 1(\mathrm{p})$ & 57 & 36 & 74 & $1.05 \times 10^{9}$ & $4.02 \times 10^{10}$ & $7.05 \times 10^{7}$ & -17 & -44 & -27 \\
\hline $\mathrm{S} 2(\mathrm{p})$ & 82 & 78 & 82 & $1.92 \times 10^{7}$ & $3.34 \times 10^{7}$ & $1.85 \times 10^{7}$ & 7 & 22 & 5 \\
\hline $\mathrm{S} 3(\mathrm{p})$ & 75 & 70 & 135 & $5.51 \times 10^{7}$ & $1.32 \times 10^{8}$ & $2.85 \times 10^{3}$ & 28 & 36 & 63 \\
\hline $\mathrm{S} 4(\mathrm{p})$ & 27 & 42 & 58 & $1.67 \times 10^{11}$ & $1.32 \times 10^{10}$ & $9.68 \times 10^{8}$ & -8 & 6 & -54 \\
\hline $\mathrm{E} 1(\mathrm{p})$ & 30 & 25 & 46 & $9.52 \times 10^{10}$ & $2.34 \times 10^{11}$ & $7.10 \times 10^{9}$ & -43 & -58 & -60 \\
\hline $\mathrm{AFE}^{*}$ & 280 & 293 & 294 & & & & & & \\
\hline
\end{tabular}

${ }^{*}$ The apparent free energy barrier (AFE) was defined as the energy difference between the highest point and the zero point in the free energy profiles. M1-M3 denote methylation reactions, D1 and D2 denote deprotonation reactions, S1-S4 denote alkyl side-chain shifting reactions, and E1 denotes olefin elimination reaction. 


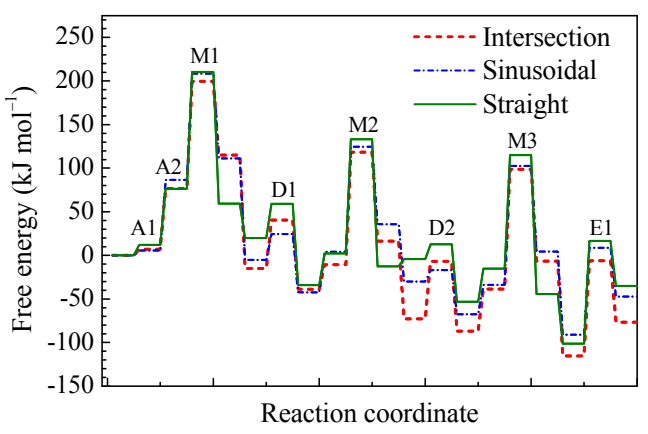

Fig. 4. Free energy profiles for propene formation via the alkene cycle of methanol-to-olefins conversion at the acid sites in the intersection cavities, sinusoidal channels, and straight channels of H-ZSM-5 zeolite at $723 \mathrm{~K} . \mathrm{A} 1$ and $\mathrm{A} 2$ denote the adsorption of methanol and co-adsorption of propene, respectively, M1-M3 denote methylation reactions, D1 and D2 denote deprotonation reactions, and E1 denotes propene elimination reaction.

tonations (D1 and D2) via the alkene cycle of MTO conversion (Fig. 2). Subsequently, propene and ethene are produced through the $\beta$-scission of higher carbenium ions, (steps E1 and E2, respectively) [58,59].

The free energy profiles and reaction data for each step of the alkene cycle of MTO conversion at the T8, T10, and T12 acid sites of H-ZSM-5 zeolite are illustrated in Fig. 4 and Table 2, and the optimized TSs of the methylation and olefin elimination steps are presented in Figs. S5 and S6. $\Delta G_{\text {int }}{ }^{\neq}$and $k$ of the rate-determining step of the M3 reaction at the T12 acid sites were $138 \mathrm{~kJ} \mathrm{~mol}^{-1}$ and $1.73 \times 10^{3} \mathrm{~s}^{-1}$, respectively, and were similar to those at the T10 acid sites for the M3 reaction (137 kJ $\mathrm{mol}^{-1}$ and $2.02 \times 10^{3} \mathrm{~s}^{-1}$, respectively) and those at the T8 acid sites for the M1 reaction $\left(134 \mathrm{~kJ} \mathrm{~mol}^{-1}\right.$ and $3.08 \times 10^{3} \mathrm{~s}^{-1}$, respectively). The $\Delta G_{\text {int }^{\neq}}$values of the D1 and D2 steps were low (13-66 kJ mol-1); therefore, these steps should play minor roles in the alkene cycle of MTO conversion. The $\Delta G_{\text {int }}{ }^{\ddagger}$ value for step E2 at the T12 acid sites was $156 \mathrm{~kJ} \mathrm{~mol}^{-1}$, which was slightly lower than those at the T8 and T10 acid sites (161 and $166 \mathrm{~kJ}$ mol-1 $^{-1}$, respectively). In contrast, the $\Delta G_{\text {int }}{ }^{\ddagger}$ value for step E1 at the T10 acid sites $\left(100 \mathrm{~kJ} \mathrm{~mol}^{-1}\right)$ was lower than those at the $\mathrm{T} 12$ and $\mathrm{T} 8$ acid sites (109 and $118 \mathrm{~kJ} \mathrm{~mol}^{-1}$, respectively).
Moreover, the AFE values at the $\mathrm{T} 12, \mathrm{~T} 10$, and $\mathrm{T} 8$ acid sites were similar (200, 208 and $209 \mathrm{~kJ} \mathrm{~mol}^{-1}$, respectively).

The similar $\Delta G_{\text {int }^{*}}$ values of the alkene cycle of MTO conversion at the T8, T10, and T12 acid sites suggested that the differences in catalytic activity and reaction probability for the alkene cycle of MTO conversion at these sites were negligible, which was different than the aromatic cycle. This was ascribed to the alkene cycle involving a relatively small TS, which was less space-demanding; consequently, the effect of the location of the acid sites in H-ZSM-5 zeolite on the $\Delta G_{\text {int }^{*}}$ value of the alkene cycle of MTO conversion was negligible.

Conversely, the $\Delta G_{\mathrm{int}^{*}}$ of step E2 (156-166 kJ mol-1) was much higher than that of step E1 (100-118 $\left.\mathrm{kJ} \mathrm{mol}^{-1}\right)$ regardless of the acid site location, suggesting that propene was the dominant product of the alkene cycle of MTO conversion over H-ZSM-5 zeolite [59]. Moreover, it appeared that the participation of ethene to the alkene cycle was insignificant, as ethene methylation required a much higher $\Delta G_{\text {int }^{*}}$ than propene methylation $[18,19]$.

\subsection{Aromatization process}

After the higher carbenium ions were formed in the alkene cycle, they can further evolve into aromatic species through the aromatization process (Fig. 2). First, the higher carbenium ions underwent deprotonation (D1) and hydride transfer (HT1) to form 1-hexene carbenium ions; thereafter, cyclohexane carbenium ions were formed through the cyclization (C1) of the olefin carbenium ion. Subsequently, the cyclohexane carbenium ion was converted to benzene via repeated deprotonation (D2-D4) and hydride transfer (HT2 and HT3) reactions.

The free energy profiles and reaction data for each step of the aromatization process at the $\mathrm{T} 8, \mathrm{~T} 10$, and $\mathrm{T} 12$ acid sites of H-ZSM-5 zeolite are presented in Fig. 5 and Table 3, and the optimized TSs of the cyclization and hydride transfer steps are depicted in Fig. S7.

It appeared that the hydride transfer reaction was the rate-determining step for the aromatization process; furthermore, $\Delta G_{\text {int }^{*}}$ of the HT2 reaction at the T12 acid sites $(137 \mathrm{~kJ}$

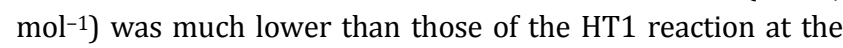

\section{Table 2}

Calculated free energy barrier $\left(\Delta G_{\text {int }^{*}}\right)$, rate constant $(k)$ and reaction free energy $\left(\Delta G_{\mathrm{R}}\right)$ for each reaction step of the formation of ethene and propene via the alkene cycle of methanol-to-olefins conversion at the acid sites in the intersection cavities (T12), sinusoidal channels (T10), and straight channels (T8) of H-ZSM-5 zeolite at $723 \mathrm{~K}$.

\begin{tabular}{|c|c|c|c|c|c|c|c|c|c|}
\hline \multirow{2}{*}{ Step } & \multicolumn{3}{|c|}{$\Delta G_{\text {int }^{*}}\left(\mathrm{~kJ} \mathrm{~mol}^{-1}\right)$} & \multicolumn{3}{|c|}{$k\left(\mathrm{~s}^{-1}\right)$} & \multicolumn{3}{|c|}{$\Delta G_{\mathrm{R}}(\mathrm{kJ} \mathrm{mol}-1)$} \\
\hline & $\mathrm{T} 12$ & $\mathrm{~T} 10$ & T8 & $\mathrm{T} 12$ & $\mathrm{~T} 10$ & T8 & $\mathrm{T} 12$ & T10 & T8 \\
\hline M1 & 123 & 122 & 134 & $1.94 \times 10^{4}$ & $2.30 \times 10^{4}$ & $3.08 \times 10^{3}$ & 38 & 25 & -17 \\
\hline M2 & 129 & 120 & 131 & $7.17 \times 10^{3}$ & $2.97 \times 10^{4}$ & $5.11 \times 10^{3}$ & 27 & 32 & -15 \\
\hline M3 & 138 & 137 & 130 & $1.73 \times 10^{3}$ & $2.02 \times 10^{3}$ & $6.07 \times 10^{3}$ & 32 & 38 & -29 \\
\hline D1 & 56 & 30 & 39 & $1.45 \times 10^{9}$ & $1.06 \times 10^{11}$ & $2.26 \times 10^{10}$ & -24 & -37 & -54 \\
\hline D2 & 66 & 13 & 17 & $2.71 \times 10^{8}$ & $1.73 \times 10^{12}$ & $9.06 \times 10^{11}$ & -14 & -38 & -49 \\
\hline E1 & 109 & 100 & 118 & $1.95 \times 10^{5}$ & $9.66 \times 10^{5}$ & $4.74 \times 10^{4}$ & 39 & 43 & 66 \\
\hline E2 & 156 & 166 & 161 & $8.97 \times 10^{1}$ & $1.41 \times 10^{1}$ & $3.51 \times 10^{1}$ & 104 & 74 & 60 \\
\hline $\mathrm{AFE}^{*}$ & 200 & 208 & 209 & & & & & & \\
\hline
\end{tabular}

${ }^{*}$ The apparent free energy barrier (AFE) was defined as the energy difference between the highest point and the zero point in the free energy profiles. M1-M3 denote methylation reactions, D1 and D2 denote deprotonation reactions, and E1 and E2 denote the propene and ethene elimination reactions, respectively. 


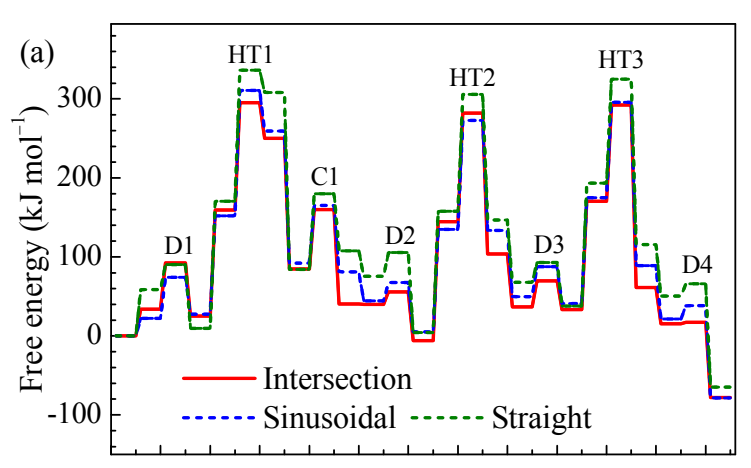

Reaction coordinate

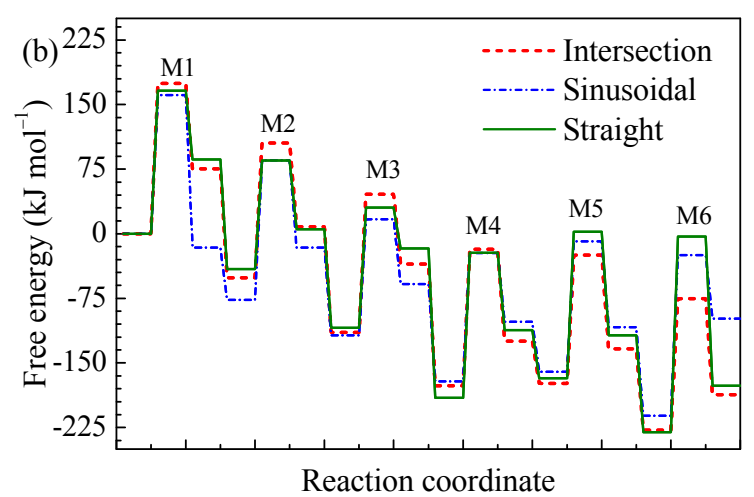

Fig. 5. Free energy profiles for the formation of (a) benzene and (b) polymethylbenzenes via the successive methylations of the benzene ring during methanol-to-olefins conversion at the acid sites in the intersection cavities, sinusoidal channels, and straight channels of $\mathrm{H}-\mathrm{ZSM}-5 \mathrm{zeolite}$ at $723 \mathrm{~K}$. Here, D1-D4 denote deprotonation reactions, HT1-HT3 denote hydride transfer reactions, C1 denotes cyclization of olefin carbenium ion, and M1-M6 denote benzene ring methylation reactions.

T10 and T8 acid sites (159 and $166 \mathrm{~kJ} \mathrm{~mol}^{-1}$, respectively). Similarly, the AFE for the aromatization process at the T12 acid sites $\left(293 \mathrm{~kJ} \mathrm{~mol}^{-1}\right)$ was much lower than those at the T10 and T8 acid sites (311 and $337 \mathrm{~kJ} \mathrm{~mol}^{-1}$, respectively), suggesting that the aromatization process occurred preferably at the T12 acid sites in the H-ZSM-5 zeolite framework.

\subsection{Successive methylations of benzene and diffusion of different species in H-ZSM-5 zeolite}

PolyMBs can be produced through successive benzene ring methylation reactions (M1-M6) (Fig. 2); the free energy profiles and reaction data for each methylation step at the T8, T10, and T12 acid sites of H-ZSM-5 zeolite are illustrated in Fig. 5 and Table 3. $\Delta G_{\text {int }}{ }^{\neq}$for the step-wise methylations of benzene to pentamethylbenzene (M1-M5) at the T12 acid sites decreased from 175 to $149 \mathrm{~kJ} \mathrm{~mol}^{-1} ; \Delta G_{\text {int }}$ for the subsequent methylation of pentamethylbenzene to hexamethylbenzene (M6) was slightly higher (153 kJ mol-1) than that for the methylation of tetramethylbenzene to pentamethylbenzene (149 $\mathrm{kJ} \mathrm{mol}^{-1}$ ). Pentamethylbenzene and hexamethylbenzene were thermodynamically more stable than other homologues at the T12 acid sites as the free surface energy decreased gradually from M1 to M6.

However, the successive methylations of the benzene ring to form higher methylated arenes were hindered by the strongly repulsive interactions in the sinusoidal and straight channels; the $\Delta G$ int $^{\neq}$values for the M6 reaction at the T10 and T8 acid

Table 3

Calculated free energy barrier $\left(\Delta G_{\text {int }^{\ddagger}}\right)$, rate constant $(k)$, and reaction free energy $\left(\Delta G_{\mathrm{R}}\right)$ for each reaction step of the formation of benzene via aromatization and the formation of polymethylbenzenes (polyMBs) via successive methylations of benzene at the acid sites in the intersection cavities (T12), sinusoidal channels (T10), and straight channels (T8) of H-ZSM-5 zeolite at $723 \mathrm{~K}$.

\begin{tabular}{|c|c|c|c|c|c|c|c|c|c|}
\hline \multirow{2}{*}{ Step } & \multicolumn{3}{|c|}{$\Delta G_{\text {int }}{ }^{ \pm}\left(\mathrm{kJ} \mathrm{mol}^{-1}\right)$} & \multicolumn{3}{|c|}{$k\left(\mathrm{~s}^{-1}\right)$} & \multicolumn{3}{|c|}{$\Delta G_{\mathrm{R}}\left(\mathrm{kJ} \mathrm{mol}^{-1}\right)$} \\
\hline & $\mathrm{T} 12$ & $\mathrm{~T} 10$ & T8 & $\mathrm{T} 12$ & $\mathrm{~T} 10$ & T8 & $\mathrm{T} 12$ & $\mathrm{~T} 10$ & T8 \\
\hline \multicolumn{10}{|c|}{ Benzene formation } \\
\hline D1 & 58 & 52 & 32 & $9.04 \times 10^{8}$ & $2.68 \times 10^{9}$ & $7.84 \times 10^{10}$ & -9 & 5 & -49 \\
\hline HT1 & 136 & 159 & 166 & $2.43 \times 10^{3}$ & $5.15 \times 10^{1}$ & $1.58 \times 10^{1}$ & 90 & 107 & 138 \\
\hline C1 & 75 & 73 & 96 & $5.57 \times 10^{7}$ & $7.88 \times 10^{7}$ & $1.79 \times 10^{6}$ & -44 & -11 & 24 \\
\hline D2 & 16 & 23 & 30 & $1.09 \times 10^{12}$ & $3.17 \times 10^{11}$ & $1.07 \times 10^{11}$ & -46 & -39 & -71 \\
\hline HT2 & 137 & 138 & 148 & $1.80 \times 10^{3}$ & $1.63 \times 10^{3}$ & $3.09 \times 10^{2}$ & -41 & -1 & -11 \\
\hline D3 & 33 & 38 & 25 & $6.25 \times 10^{10}$ & $2.64 \times 10^{10}$ & $2.39 \times 10^{11}$ & -3 & -9 & -30 \\
\hline HT3 & 122 & 121 & 132 & $2.43 \times 10^{4}$ & $2.78 \times 10^{4}$ & $4.54 \times 10^{3}$ & -109 & -86 & -78 \\
\hline D4 & 2 & 17 & 16 & $1.14 \times 10^{13}$ & $9.31 \times 10^{11}$ & $1.13 \times 10^{12}$ & -93 & -100 & -115 \\
\hline $\mathrm{AFE}^{*}$ & 293 & 311 & 337 & & & & & & \\
\hline \multicolumn{10}{|c|}{ PolyMBs formation } \\
\hline M1 & 175 & 161 & 166 & $3.71 \times 10^{0}$ & $3.59 \times 10^{1}$ & $1.52 \times 10^{1}$ & 75 & -16 & 86 \\
\hline M2 & 157 & 162 & 126 & $7.39 \times 10^{1}$ & $2.86 \times 10^{1}$ & $1.24 \times 10^{4}$ & 59 & 61 & 46 \\
\hline M3 & 161 & 135 & 140 & $3.80 \times 10^{1}$ & $2.81 \times 10^{1}$ & $1.20 \times 10^{3}$ & 79 & 59 & 92 \\
\hline M4 & 159 & 149 & 168 & $5.13 \times 10^{1}$ & $2.73 \times 10^{2}$ & $1.06 \times 10^{1}$ & 20 & 26 & 30 \\
\hline M5 & 149 & 151 & 170 & $2.73 \times 10^{2}$ & $1.70 \times 10^{2}$ & $7.77 \times 10^{0}$ & 15 & 20 & 19 \\
\hline M6 & 153 & 186 & 227 & $1.37 \times 10^{2}$ & $5.21 \times 10^{-1}$ & $5.70 \times 10^{-4}$ & 16 & 43 & 21 \\
\hline
\end{tabular}

${ }^{*}$ The apparent free energy barrier (AFE) was defined as the energy difference between the highest point and the zero point in the free energy profiles. D1-D4 denote deprotonation reactions, HT1-HT3 denote hydride transfer reactions, C1 denotes cyclization of olefin carbenium ion, and M1-M6 denote benzene ring methylation reactions. 
sites (186 and $227 \mathrm{~kJ} \mathrm{~mol}^{-1}$, respectively) were much higher than that at the T12 acid sites $\left(153 \mathrm{~kJ} \mathrm{~mol}^{-1}\right)$. These results indicated that benzene and polyMBs can be easily produced in the intersection cavities, whereas the formation of these aromatic species, particularly higher polyMBs, was thermodynamically and kinetically unfavorable in the sinusoidal and straight channels; these results were in agreement with the data reported by Liang et al. [45] and Chen et al. [62].

In addition, the diffusion of higher polyMBs in the pore channels of H-ZSM-5 zeolite was rather difficult. The trajectories and density maps revealed that hexamethylbenzene, once formed, was exclusively aggregated in the intersection cavities (Fig. 6). Although lower polyMBs (e.g., $p$-xylene) can diffuse more easily and spread along the straight channels, they were still mainly present in the intersection cavities. Consequently, the aromatic HCP species (dominated by polyMBs) were probably trapped in the intersection cavities, which were the main place to interact with methanol to produce light olefins via the aromatic cycle. Brogaard et al. [63] also observed that the intersection cavities of H-ZSM-5 zeolite were the preferred adsorption sites for arene species. In contrast, the distribution probabilities of propene molecules in the intersection cavities, straight channels, and sinusoidal channels were similar, indicating that propene can interact with methanol to form light olefins via the alkene cycle at all three types of acid sites.

Current calculation results demonstrated that for MTO conversion over H-ZSM-5 zeolite, the aromatic cycle and aromatization process occurred preferentially at the T12 acid sites instead of the T10 and T8 acid sites. In contrast, the alkene
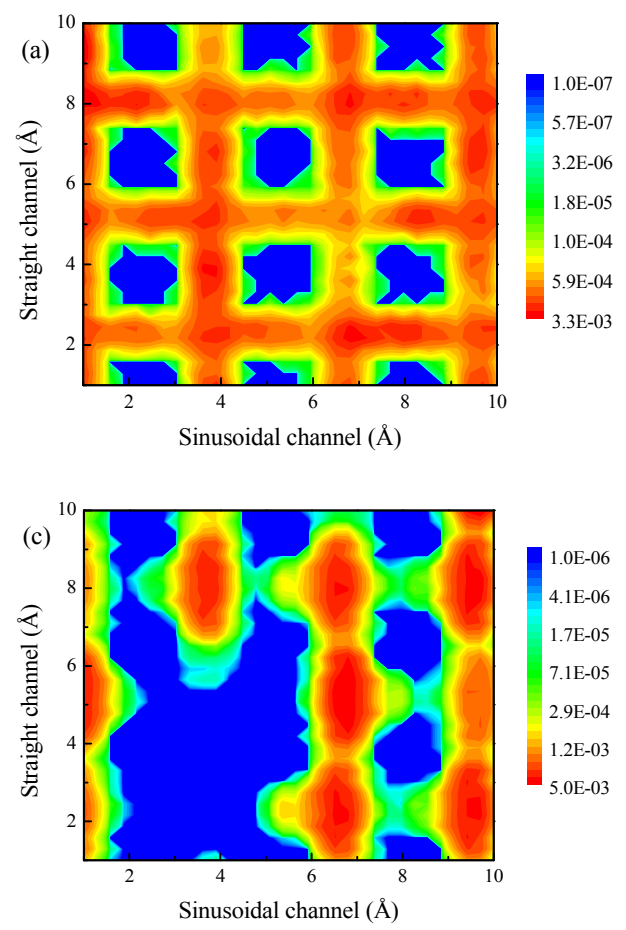

cycle can occur at all acid sites with similar probability. Although the calculated substitution energy and occupation probability suggested that $\mathrm{Al}$ atoms were preferentially located at the intersectional T sites (T12, T9 and T2 + T3) of H-ZSM-5 zeolite $[37,47]$, the actual location of $\mathrm{Al}$ atoms or distribution of acid sites were strongly affected by the kinetic parameters of the gelling and crystallization processes [29-31]. Therefore, the location of the $\mathrm{Al}$ atoms or distribution of acid sites in zeolite frameworks can be regulated purposively by elaborately controlling the synthesis parameters. However, it is still difficult to fabricate H-ZSM-5 zeolite with a uniform distribution of acid sites in practice. Modern characterization techniques, such as Fourier-transform infrared spectroscopy, ${ }^{27} \mathrm{Al}$ and ${ }^{29} \mathrm{Si}$ multiple quantum magic-angle spinning nuclear magnetic resonance spectroscopy, and diffuse reflectance ultraviolet-visible spectroscopy of $\mathrm{Co}^{2+-}$ exchanged samples, have allowed to reliably determine the fractions of acid sites distributed in different pore channels and correlate them with the catalytic behavior of H-ZSM-5 zeolite.

Our calculation results suggested that the catalytic performance of H-ZSM-5 zeolite for MTO conversion, including activity and product selectivity, can be properly regulated by altering the location of $\mathrm{Al}$ atoms or the distribution of acid sites in the framework. An increase in the fraction of intersection cavity (represented by T12) acid sites can promote the hydride transfer and arene methylation reactions and produce more aromatic HCP species, which favor the propagation of the aromatic cycle. In contrast, when the fractions of sinusoidal and straight channel (represented by T10 and T8) acid sites were
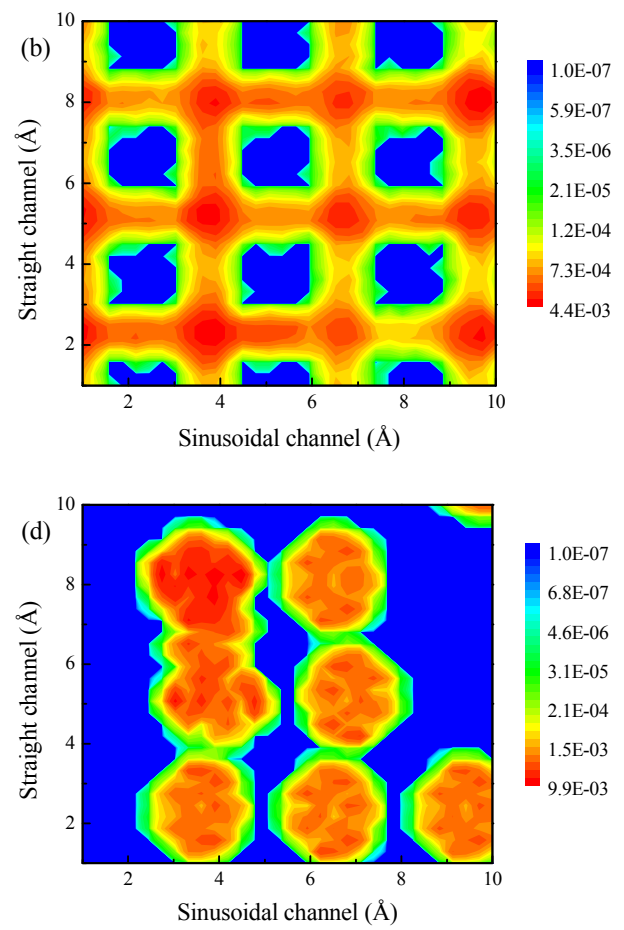

Fig. 6. Contour lines for the diffusion of (a) methanol, (b) propene, (c) p-xylene, and (d) hexamethylbenzene molecules in the straight and sinusoidal channels of H-ZSM-5 zeolite at $723 \mathrm{~K}$. The density maps were constructed according to the two-dimensional projections of the mass centers of guest molecules in a $2 \times 2 \times 2$ supercell. The color bars represent the density of guest molecules distributed in different channels with the unit of 1 ; the red areas with higher density values indicate higher diffusion probability. 
higher, the alkene cycle was relatively favored, which enhanced selectivity for propene and higher alkenes. These results were in good agreement with previously reported experimental data, as follows. Olsbye et al. $[19,20]$ performed a ${ }^{12} \mathrm{C} /{ }^{13} \mathrm{C}$ switching experiment and reported that during MTO conversion over H-ZSM-5 zeolite, ethene, xylene, and trimethylbenzene evolved simultaneously, whereas propene and higher alkenes were mainly generated from the alkene methylation and interconversion (e.g., cracking) reactions. Bhan et al. [64] performed ${ }^{13} \mathrm{C}$-propene and ${ }^{13} \mathrm{C}$-toluene co-feeding experiments and reported that the selectivity for ethene, propene, and aromatics of MTO conversion can be effectively tuned by altering the contributions of the aromatic and alkene cycles. Liang et al. [45] and Kim et al. [46] performed in situ spectroscopy, isotopic-labeling experiments, and DFT calculations and revealed that changes in the acid sites distribution of H-ZSM-5 zeolite significantly affected the MTO reaction pathways and relative contributions of the aromatic and alkene cycles. If the number of intersection cavity acid sites of H-ZSM-5 zeolite was higher, the formation of aromatic intermediates, such as polyMBs, would be promoted, the aromatic cycle would be favored, and, therefore, the ethene-to-propene ratio in the MTO conversion products would increase; conversely a higher number of sinusoidal and straight channel acid sites would favor the alkene cycle and produce more propene and $\mathrm{C}_{3+}$ alkenes.

\section{Conclusions}

The catalytic behavior of the T8, T10, and T12 acid sites (representing the straight channel, sinusoidal channel and intersection cavity, respectively) of H-ZSM- 5 zeolite for the MTO reaction network, involving an aromatic cycle, alkene cycle, and aromatization process, was comparatively investigated using DFT calculations and MD simulations.

The results indicated that the catalytic performances of the T8, T10, and T10 acid sites of H-ZSM-5 zeolite were rather different, which can be explained by the dual-cycle HCP mechanism. The aromatic cycle and aromatization process were favored at the T12 sites (intersection cavity) with a lower energy barrier than the T10 and T8 acid sites (straight and sinusoidal channels, respectively), whereas the alkene cycle could occur at all three types of acid sites with similar energy barriers and reaction probabilities. Consequently, an increase in the number of intersection cavity acid sites can promote the formation of polyMBs and the propagation of the aromatic cycle, which produced more ethene. In contrast, the increase in the numbers of sinusoidal and straight channel acid sites favored the alkene cycle and, therefore enhanced selectivity for propene and higher alkenes.

This study helps to elucidate the relation between the catalytic performance of specific acid sites and their locations in the H-ZSM-5 zeolite framework for MTO conversion. Based on our findings, we proposed that the performance of zeolite catalysts for MTO conversion, including the activity, lifetime, and particularly the product selectivity, can be properly tuned through purposive regulation of the distribution of acid sites in the zeolite framework.

\section{Acknowledgments}

The authors thank Dr. De Wispelaere of the Center for Molecular Modeling (CMM), Ghent University for the kind help in the analysis of the results of density functional theory (DFT) calculation and molecular dynamic (MD) simulation. The calculations are performed on the Computer Network Information Center of Chinese Academy of Sciences, and National Supercomputer Centers in Lüliang of China.

\section{Declaration of competing interest}

The authors declare that they have no known competing financial interests or personal relationships that could have appeared to influence the work reported in this paper.

\section{Electronic supporting information}

Supporting information is available in the online version of this article, such as calculated proton affinity, methanol adsorption energy and ammonia adsorption energy on different acid sites in H-ZSM-5, as well as the optimized transition states for the main reaction steps for MTO on different acid sites in H-ZSM-5.

\section{References}

[1] D. A. Hickman, L. D. Schmidt, Science, 1993, 259, 343-346.

[2] N. M. Laurendeau, Progr. Energy Combust. Sci., 1978, 4, 221-270.

[3] I. M. Dahl, S. Kolboe, J. Catal., 1996, 161, 304-309.

[4] S. Xu, Y. Zhi, J. Han, W. Zhang, X. Wu, T. Sun, Y. Wei, Z. Liu, Adv. Catal., 2017, 61, 37-122.

[5] Y. Liu, D. Deng, X. Bao, Chem, 2020, 6, 2497-2514.

[6] J. Haw, W. Song, D. Marcus, J. Nicholas, Acc. Chem. Res., 2003, 36, 317-326.

[7] U. Olsbye, S. Svelle, M. Bjørgen, P. Beato, T. V. W. Janssens, F. Joensen, S. Bordiga, K. P. Lillerud, Angew. Chem. Int. Ed., 2012, 51, 5810-5831.

[8] V. Van Speybroeck, K. De Wispelaere, J. Van der Mynsbrugge, M. Vandichel, K. Hemelsoet, M. Waroquier, Chem. Soc. Rev., 2014, 43, 7326-7357.

[9] U. Olsbye, S. Svelle, K. Lillerud, Z. Wei, Y. Chen, J. Li, J. Wang, W. Fan, Chem. Soc. Rev., 2015, 44, 7155-7176.

[10] P. Tian, Y. Wei, M. Ye, Z. Liu, ACS Catal., 2015, 5, 1922-1938.

[11] J. Li, Z. Wei, Y. Chen, B. Jing, Y. He, M. Dong, H. Jiao, X. Li, Z. Qin, J. Wang, W. Fan, J. Catal., 2014, 317, 277-283.

[12] A. Comas-Vives, M. Valla, C. Coperet, P. Sautet, ACS Central Sci., 2015, 1, 313-319.

[13] Y. Liu, S. Muller, D. Berger, J. Jelic, K. Reuter, M. Tonigold, M. Sanchez-Sanchez, J. A. Lercher, Angew. Chem. Int. Ed., 2016, 55, 5723-5726.

[14] A. D. Chowdhury, K. Houben, G. T. Whiting, M. Mokhtar, A. M. Asiri, S. A. Al-Thabaiti, S. N. Basahe, M. Baldus, B. M. Weckhuysen, Angew. Chem. Int. Ed., 2016, 55, 15840-15845.

[15] P. N. Plessow, F. Studt, ACS Catal., 2017, 7, 7987-7994.

[16] X. Wu, S. Xu, W. Zhang, J. Huang, J. Li, B. Yu, Y. Wei, Z. Liu, Angew. Chem. Int. Ed., 2017, 56, 9039-9043.

[17] S. Wang, Y. Chen, Z. Qin, T. Zhao, S. Fan, M. Dong, J. Li, W. Fan, J. Wang, J. Catal., 2019, 369, 382-395.

[18] S. Svelle, F. Joensen, J. Nerlov, U. Olsbye, K. Lillerud, S. Kolboe, M. 


\section{Graphical Abstract}

Chin. J. Catal., 2021, 42: 1126-1136 doi: 10.1016/S1872-2067(20)63732-9

Catalytic roles of the acid sites in different pore channels of H-ZSM-5 zeolite for methanol-to-olefins conversion

Sen Wang, Zhikai Li, Zhangfeng Qin*, Mei Dong, Junfen Li, Weibin Fan *, Jianguo Wang *

Institute of Coal Chemistry, Chinese Academy of Sciences; University of the Chinese Academy of Sciences

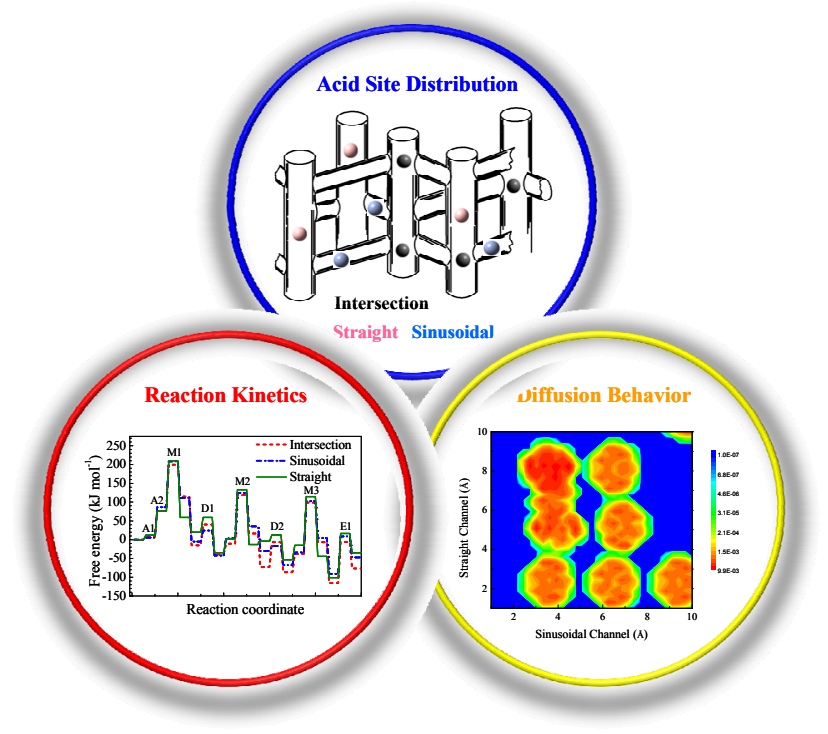

The aromatic cycle and aromatization reaction of MTO conversion over H-ZSM-5 zeolite occurred preferentially in the intersection cavities, whereas the alkene cycle occurred with the same probability in the intersection cavities, straight channels, and sinusoidal channels.

Bjogen, J. Am. Chem. Soc., 2006, 128, 14770-14771.

[19] M. Bjørgen, S. Svelle, F. Joensen, J. Nerlov, S. Kolboe, F. Bonino, L. Palumbo, S. Bordiga, U. Olsbye, J. Catal., 2007, 249, 195-207.

[20] M. Bjørgen, S. Akyalcin, U. Olsbye, S. Benard, S. Kolboe, S. Svelle, J. Catal., 2010, 275, 170-180.

[21] J. Martinez-Espin, K. De Wispelaere, T. Janssens, S. Sevlle, K. Lillerud, P. Beato, V. Van Speybroeck, U. Olsbye, ACS Catal., 2017, 7, 5773-5780.

[22] S. Ilias, A. Bhan, J. Catal., 2014, 311, 6-16.

[23] C. Wang, Y. Chu, A. Zheng, J. Xu, Q. Wang, P. Gao, G. Qi, Y. Gong, F. Deng, Chem. Eur. J., 2014, 20, 12432-12443.

[24] W. Dai, C. Wang, M. Dyballa, G. Wu, N. Guan, L. Li, Z. Xie, M. Hunger, ACS Catal., 2015, 5, 317-326.

[25] M. Zhang, S. Xu, J. Li, Y. Wei, Y. Gong, Y. Chu, A. Zheng, J. Wang, W. Zhang, X. Wu, Z. Liu, J. Catal., 2016, 335, 47-57.

[26] R. M. Dessau, J. Catal., 1986, 99, 111-116.

[27] D. McCann, D. Lesthaeghe, P. F. Kletnieks, D. R. Guenther, M. J. Hayman, V. Van Speybroeck, M. Waroquier, J. F. Haw, Angew. Chem. Int. Ed., 2008, 47, 5179-5182.

[28] D. Lesthaeghe, J. Van der Mynsbrugge, M. Vandichel, M. Waroquier, V. Van Speybroeck, ChemCatChem, 2011, 3, 208-212.

[29] J. Dedecek, Z. Sobalik, B. Wichterlova, Catal. Rev. Sci. Eng., 2012, 54, 135-223.

[30] B. C. Knott, C. T. Nimlos, D. J. Robichaud, M. R. Nimlos, S. Kim, R. Gounder, ACS Catal., 2018, 8, 770-784.

[31] S. Wang, Y. He, W. Jiao, J. Wang, W. Fan, Curr. Opin. Chem. Eng., 2019, 23, 146-154.
[32] A. Bhan, E. Iglesia, Acc. Chem. Res., 2008, 41, 559-567.

[33] A. Janda, A. T. Bell, J. Am. Chem. Soc., 2013, 135, 19193-19207.

[34] S. Mallikarjun Sharada, P. M. Zimmerman, A. T. Bell, M. Head-Gordon, J. Phys. Chem. C, 2013, 117, 12600-12611.

[35] J. R. Di Iorio, C. T. Nimlos, R. Gounder, ACS Catal., 2017, 7, 6663-6674.

[36] T. Biligetu, Y. Wang, T. Nishitoba, R. Otomo, S. Park, H. Mochizuki, J. N. Kondo, T. Tatsumi, T. Yokoi, J. Catal., 2017, 353, 1-10.

[37] S. Wang, P. Wang, Z. Qin, Y. Chen, M. Dong, J. Li, K. Zhang, P. Liu, J. Wang, W. Fan, ACS Catal., 2018, 8, 5485-5505.

[38] F. Jiao, X. L. Pan, K. Gong, Y. X. Chen, G. Li, X. H. Bao, Angew. Chem. Int. Ed., 2018, 57, 4692-4696.

[39] J. Chen, T. Liang, J. Li, S. Wang, Z. Qin, P. Wang, L. Huang, W. Fan, J. Wang, ACS Catal., 2016, 6, 2299-2313.

[40] X. Zhao, L. Wang, J. Li, S. Xu, W. Zhang, Y. Wei, X. Guo, P. Tian, Z. Liu, Catal. Sci. Technol., 2017, 7, 5882-5892.

[41] C. G. Li, A. Vidal-Moya, P. J. Miguel, J. Dedecek, M. Boronat, A. Corma, ACS Catal., 2018, 8, 7688-7697.

[42] M. Yoshioka, T. Yokoi, T. Tatsumi, ACS Catal., 2015, 5, 4268-4275.

[43] L. Zhang, S. Wang, D. Shi, Z. Qin, P. Wang, G. Wang, J. Li, M. Dong, W. Fan, J. Wang, Catal. Sci. Technol., 2020, 10, 1835-1847.

[44] Z. J. Wu, K. Q. Zhao, Y. Zhang, T. Pan, S. H. Ge, Y. N. Ju, T. S. Li, T. Dou, Ind. Eng. Chem. Res., 2019, 58, 10737-10749.

[45] T. Liang, J. Chen, Z. Qin, J. Li, P. Wang, S. Wang, G. Wang, M. Dong, W. Fan, J. Wang, ACS Catal., 2016, 6, 7311-7325.

[46] S. Kim, G. Park, M. Woo, G. Kwak, S. K. Kim, ACS Catal., 2019, 9, 
2880-2892.

[47] S. Wang, S. Li, L. Zhang, Z. Qin, Y. Chen, M. Dong, J. Li, W. Fan, J. Wang, Catal. Sci. Technol., 2018, 8, 3193-3204.

[48] M. J. Frisch, G. W. Trucks, H. B. Schlegel, G. E. Scuseria, M. A. Robb, J. R. Cheeseman, G. Scalmani, V. Barone, B. Mennucci, G. A. Petersson, H. Nakatsuji, M. Caricato, X. Li, H. P. Hratchian, A. F. Izmaylov, J. Bloino, G. Zheng, J. L. Sonnenberg, M. Hada, M. Ehara, K. Toyota, R. Fukuda, J. Hasegawa, M. Ishida, T. Nakajima, Y. Honda, O. Kitao, H. Nakai, T. Vreven, J. A. Montgomery, Jr, J. E. Peralta, F. Ogliaro, M. Bearpark, J. J. Heyd, E. Brothers, K. N. Kudin, V. N. Staroverov, R. Kobayashi, J. Normand, K. Raghavachari, A. Rendell, J. C. Burant, S. S. Iyengar, J. Tomasi, M. Cossi, N. Rega, N. J. Millam, M. Klene, J. E. Knox, J. B. Cross, V. Bakken, C. Adamo, J. Jaramillo, R. Gomperts, R. E. Stratmann, O. Yazyev, A. J. Austin, R. Cammi, C. Pomelli, J. W. Ochterski, R. L. Martin, K. Morokuma, V. G. Zakrzewski, G. A. Voth, P. Salvador, J. J. Dannenberg, S. Dapprich, A. D. Daniels, O. Farkas, J. B. Foresman, J. V. Ortiz, J. Cioslowski and D. J. Fox, Gaussian 09, revision E.01; Gaussian, Inc., Wallingford CT, 2009.

[49] J. D. Chai, M. Head-Gordon, Phys. Chem. Chem. Phys., 2008, 10, 6615-6620.

[50] L. Goerigk, S. Grimme, Phys. Chem. Chem. Phys., 2011, 13, 6670-6688.
[51] H. Eyring, J. Chem. Phys., 1935, 3, 107-115.

[52] Materials Studio Vol. 7.0. Accelrys Software Inc., San Diego, CA 92121, USA.

[53] H. Sun, J. Phys. Chem. B, 1998, 102, 7338-7364.

[54] C. Wang, B. Li, Y. Wang, Z. Xie, J. Energy Chem., 2013, 22, 914-918.

[55] P. P. Ewald, Ann. Phys., 1921, 64, 253-287.

[56] A. J. Jones, R. T. Carr, S. I. Zones, E. Iglesia, J. Catal., 2014, 312, 58-68.

[57] A. Ghorbanpour, J. D. Rimer, L. C. Grabow, ACS Catal., 2016, 6, 2287-2298.

[58] K. De Wispelaere, K. Hemelsoet, M. Waroquier, V. Van Speybroeck, J. Catal., 2013, 305, 76-80.

[59] S. Wang, Y. Chen, Z. Wei, Z. Qin, H. Ma, M. Dong, J. Li, W. Fan, J. Wang, J. Phys. Chem. C, 2015, 119, 28482-28498.

[60] S. Kozuch, S. Shaik, Acc. Chem. Res., 2011, 44, 101-110.

[61] C. Wang, Y. Wang, Y. Du, G. Yang, Z. Xie, Catal. Sci. Technol, 2015, 5, 4354-4364.

[62] Y. Chen, X. Zhao, Z. Qin, S. Wang, Z. Wei, J. Li, M. Dong, J. Wang, W. Fan, J. Phys. Chem. C, 2020, 124, 13789-13798.

[63] R. Y. Brogaard, B. M. Weckhuysen, J. K. Norskov, J. Catal., 2013, 300, 235-241.

[64] S. Ilias, A. Bhan, J. Catal., 2012, 290, 186-192.

\section{H-ZSM-5分子篮不同孔道处的酸位在甲醇制烯烃反应中的催化作用

\author{
王 森, 李志凯 ${ }^{\mathrm{a}}$, 秦张峰, ${ }^{\mathrm{a}}{ }^{*}$, 董 梅 ${ }^{\mathrm{a}}$, 李俊汾 ${ }^{\mathrm{a}}$, 樊卫斌, 井, 王建国 ${ }^{\mathrm{a}, \mathrm{b}, \mathrm{S}}$ \\ a中国科学院山西煤炭化学研究所, 煤转化国家重点实验室, 山西太原 030001
} \\ ${ }^{\mathrm{b}}$ 中国科学院大学, 北京 100049}

摘要: 甲醇制烯烃(MTO)作为一条由煤、天然气和生物质等含碳资源制备重要有机化学品的非石油路线,近年来备受关注. 作为MTO催化剂, 分子笚的骨架拓扑结构和酸性质对于其催化活性、反应路径和产物分布等具有重要的影响. H-ZSM-5分 子篎是一种典型的MTO反应催化剂, 酸位可以分布在MFI拓扑结构的直孔道、正弦孔道和交叉位点处. 虽然目前已普遍认 可MTO反应遵循芳烃/烯烃双循环烃池机理, 分子篮的催化性能与其骨架中酸中心的位置相关, 但对于H-ZSM-5分子篮不 同孔道位置处的酸中心在甲醇制烯烃反应中的催化作用仍缺乏足够认识.

本文采用密度泛函理论计算和分子动力学模拟方法, 对H-ZSM-5分子篮不同孔道处(包括正弦孔道、直孔道和交叉腔) 酸位中心上的MTO反应网络(包括芳烃循环、烯烃循环和芳构化)及甲醇原料和烯烃/芳烃产物的扩散行为进行了比较研究. 结果表明, 与正弦孔道和直孔道相比, 芳烃循环和芳构化反应在交叉腔的酸中心上因具有较低的能垒而更易进行. 相比之 下, 在正弦孔道和直孔道中, 多甲基苯的生成受到显著限制, 而烯烃循环却可以在三种酸中心(正弦孔道、直孔道和交叉腔) 上以相近的能垒和相似的几率进行. 芳烃循环生成乙烯和丙烯的几率相近, 而烯烃循坏产物以丙烯和较高的烯烃产物为 主. 落位于H-ZSM-5交叉腔的酸中心能促进芳烃中间体如多甲基苯的生成, 推动芳烃循环, 提高乙烯选择性, 而正弦孔道和 直孔道中的酸中心则能增强烯烃循环, 生成较多的丙烯和较高的烯烃产物. 因此, H-ZSM-5分子篎对MTO的催化性能(包 括活性和产物选择性等), 可以通过有目的地调节酸中心在分子篮骨架中的位置分布(即铝落位)而得到有效调变和提升.

本文阐明了 H-ZSM-5 分子篮酸中心在MTO反应中的催化作用与其骨架中的落位之间的有机联系, 为高效甲醇转化分 子篮催化剂的设计和性能提升提供了参考思路.

关键词: 甲醇制烯烃; H-ZSM-5分子笁; 酸位分布; 密度泛函理论计算; 分子动力学模拟

收稿日期: 2020-09-14. 接受日期: 2020-11-10. 上网时间: 2021-03-05.

*通讯联系人. 电话: (0351)4046092; 电子信箱: qzhf@sxicc.ac.cn

\#通讯联系人. 电话: (0351)4199009; 电子信箱: fanwb@sxicc.ac.cn

通讯联系人. 电话: (0351)4199009; 电子信箱: iccjgw@sxicc.ac.cn

基金来源：国家重点研发计划(2018YFB0604802); 国家自然科学基金(21991092, 21991090, U1910203, 21802157); 山西省自然科 学基金(201901D211581); 山西省优秀博士生(BK2018001); 煤转化国家重点实验室自主研究项目(2020BWZ004).

本文的电子版全文由Elsevier出版社在ScienceDirect上出版(http://www.sciencedirect.com/journal/chinese-journal-of-catalysis). 